\title{
Resistencia no violenta para una sociedad igualitaria y sostenible: el pensamiento de Petra Kelly
}

\author{
Non-violent resistance for equal and sustainable society: \\ Petra Kelly's thinking
}

ANGÉLICA VELASCO SESMA*

\begin{abstract}
Resumen: El problema de la guerra y de la violencia ha sido tratado por la ética desde diversos enfoques. Desde una postura pacifista, Petra Kelly ha señalado que este problema está estrechamente relacionado con la degradación ambiental, la violación de los derechos humanos, el aumento de la injusticia en el mundo y la desigualdad entre los sexos. El análisis que realiza de estos fenómenos, así como sus propuestas ético-políticas, nos proveen de elementos valiosos a la hora de trabajar por la justicia social, la igualdad y la sostenibilidad. Palabras clave: Resistencia no violenta, degradación ambiental, mujeres, justicia, igualdad.
\end{abstract}

\begin{abstract}
Ethics has addressed the problem of war and violence from several perspectives. From a pacifist stance, Petra Kelly noted that this problem is closely related to environmental damage, the violation of human rights, the growth of injustice in the world and inequality between the sexes. Her analysis of these issues and the ethical and political solutions she proposes to remedy them, provide valuable ground for the development of social justice, equality and sustainability.
\end{abstract}

Key words: Non-violent resistance, environmental degradation, women, justice, equality.

\section{Introducción}

En estos momentos en los que resurge el peligro del enfrentamiento entre las grandes potencias y el retorno a las amenazas de la Guerra Fría, las propuestas para la resolución no violenta de los conflictos y la reflexión ética sobre las cuestiones relacionadas con la guerra y con la paz se muestran de vital importancia. En el libro recientemente publicado, Paz para la paz. Prolegómenos a una filosofía contemporánea sobre la guerra, se nos recuerda la necesidad de reformular la idea de la paz, de forma que se entienda como un orden que aspira

Fecha de recepción: 30/05/2014. Fecha de aceptación: 19/11/2014.

* Miembro de la Cátedra de Estudios de Género de la Universidad de Valladolid. E-mail: angelica.velasco. sesma@gmail.com. Sus líneas de investigación son la Filosofía Social, la Ética Ambiental y los Estudios de Género. Entre sus publicaciones recientes destacan: Velasco Sesma, A. (2013), «Desarrollo y medio ambiente en clave de género», en: Garrido Gómez, M. I. (ed.): El derecho humano al desarrollo, Madrid, Tecnos, pp. 273-296, y Velasco Sesma, A. (2014), «Más allá del mecanicismo: heroínas ecológicas del imaginario actual», en: Puleo, A. (ed.): Ecología y género en diálogo interdisciplinar, Madrid, Plaza y Valdés, pp. 341-358.

Este trabajo se enmarca en el proyecto I+D Prismas filosófico-morales de las crisis. Hacia una nueva pedagogía sociopolítica (Ref. FFI2013-42935-P) (Entidad financiadora: MICINN) y en el programa de becas FPI de la Universidad de Valladolid. 
explícitamente a liberarse de la dominación y de la injusticia (Ródenas, 2014a). Sólo puede considerarse que una sociedad está en paz cuando se ha logrado un orden democrático, en el que todos los miembros de la sociedad cuentan con la misma libertad. La paz, necesariamente, tiene que ser paz con justicia (Ródenas, 2014b). No se reduce, pues, a ser ausencia de guerra, sino que exige que se elimine la dominación en todos los ámbitos de la sociedad, tanto a nivel nacional como internacional. Como Johan Galtung señalara, la violencia estructural es incompatible con un estado de paz verdadera (Galtung, 1985). Javier Muguerza, por su parte, ha afirmado que, si somos rigurosos, no podemos hablar de «guerras justas» pues, dado que la guerra se basa en la violencia, nunca será buena en igual medida para los que padecen la violencia y para los que la ejercen (Muguerza, 2004). De hecho, considera que la ética no debe justificar ninguna clase de violencia ${ }^{1}$. Sin embargo, dado que en ocasiones se ha afirmado, como apunta Jeff McMahan (McMahan, 2004), que no parece apropiada ni la parcialidad absoluta ni la imparcialidad perfecta en lo que respecta a la importancia que se otorga a los intereses de los ciudadanos del propio Estado y del resto de los Estados, la teoría moral tendrá que determinar cuáles son las condiciones que justifican que un Estado conceda prioridad a sus propios intereses por encima de los de los demás Estados. Esto presupone que algunas formas de parcialidad nos parecen moralmente justificables y que la guerra, en determinados casos, es permisible. Con este fin, se ha desarrollado la teoría de la guerra justa que mantiene que el uso de la violencia por el Estado está legitimado cuando los fines sean justos y los medios se atengan a las limitaciones adecuadas.

Desde el pensamiento pacifista, por el contrario, se defiende que la inmoralidad de la guerra depende de la naturaleza inherente del acto en sí, de forma que no puede justificarse jamás, sean cuales sean sus consecuencias reales o esperadas. Podemos comprobar que, dentro del pacifismo, las mujeres han tenido un peso importante a lo largo de la historia. Durante el siglo XIX surgieron en diferentes países sociedades autónomas de mujeres por la paz (como las Female Auxiliary Peace Societies o la Ligue Intenationale de la Paix et de la Liberté). En 1915, se celebró en La Haya un congreso internacional de mujeres que suponía una protesta contra la guerra y un intento de buscar alternativas para acabar con ella. Fue un congreso de gran éxito en el que participaron mujeres de doce países. Los temas fundamentales que se trataron fueron el control democrático de la política exterior, la posibilidad de negociar la paz y el sufragio femenino. Propusieron una serie de medidas para la paz y celebraron un segundo congreso tras la finalización de la guerra. Las mujeres se organizaron en la Liga Internacional de Mujeres por la Paz y la Libertad (WILPF) que sigue, en nuestros días, realizando acciones a favor de la paz, que se entrelazan con campañas por la sostenibilidad ambiental y por la justicia económica y social global.

En 1980, dos mil mujeres, muchas de ellas pertenecientes a la Liga Internacional, marcharon ante el Pentágono como rechazo a la Guerra Fría, a la carrera armamentística y a las pruebas nucleares. Entre 1981 y 1994, en Gran Bretaña, un campamento pacifista de mujeres se asentó en torno a las bases militares de Greenham Common. Mediante una lucha constante y original, consiguieron el desmantelamiento de los misiles de la OTAN.

1 En este sentido, sostiene que las guerras defensivas tampoco serán justas en ningún caso, sino que lo único que se puede decir de ellas es que son «males necesarios», pero, en tanto que «males», es imposible justificarlas moralmente. 
El movimiento pacifista, como vemos, ha contado con gran representación femenina. Los principios feministas aportan una visión imprescindible y enriquecedora al movimiento por la paz. La ecofeminista Petra Kelly (Günzburg, Bavaria, 1947-Bonn, 1992) aparece como una figura esencial al tratar el movimiento pacifista en su unión con las reivindicaciones feministas y con las demandas ecologistas ${ }^{2}$. Kelly une en su pensamiento muchas de las problemáticas que hicieron surgir el ecofeminismo ${ }^{3}$. Su producción intelectual, así como su lucha como activista, se centran en las injusticias que surgen de la imposición de un tipo de poder jerárquico y patriarcal. Así, entre sus preocupaciones fundamentales encontramos la militarización de la sociedad, la energía nuclear, el incumplimiento de los derechos humanos, la degradación ambiental y el deterioro de la salud que de ésta se deriva, la insostenibilidad del sistema productivo y la desigualdad entre los sexos. En estas líneas pretendo aportar una revisión crítica del pensamiento de Kelly con el fin de encontrar en él elementos valiosos que nos ayuden a trabajar por la consecución de una sociedad justa, pacífica, igualitaria y ecológicamente sostenible.

\section{Militarismo, pacifismo y transformación política}

El militarismo, el rearme y la energía nuclear conducen inevitablemente a una situación de violencia y vulnerabilidad que pone en peligro a la humanidad y al planeta. Por ello, Kelly desarrolla una crítica a este sistema violento que constituye un despilfarro tanto desde el punto de vista económico - pues se invierten medios que podrían utilizarse para industrias civiles sostenibles- como social -ya que las personas que se dedican a trabajar en la industria militar podrían emplear su ingenio en otro tipo de trabajos-. En su opinión (Kelly, 1990), esos recursos deberían emplearse en desarrollar técnicas para proteger el medio ambiente, en explorar fuentes de energía alternativa y en prevenir las enfermedades y la pobreza.

Uno de los asuntos que resalta como de los más preocupantes de la forma de hacer política es la política de seguridad que, en realidad, conduce a la humanidad a la más extrema inseguridad. Su postura es radicalmente opuesta a la de Maquiavelo. El autor de El Príncipe resalta la importancia de la violencia y la fuerza para el mantenimiento del poder estatal (Maquiavelo, 1987). El Estado, afirma, posibilita que los ciudadanos puedan vivir sin aniquilarse pero, dada la naturaleza violenta de las relaciones humanas, necesita de las armas para formarse y mantenerse. Así, la fuerza militar contribuye a la defensa del

2 Kelly no es la única ecofeminista que trata estos temas. También algunas ecofeministas clásicas, como Andrée Collard, se acercan al tema de la guerra, aunque proponiendo explicaciones biologicistas. Katarina Lappänen (Lappänen, 2004) considera que el libro Alarm Clock (1941) de Elin Wägner es un texto ecofeminista. Wägner, que participó en el movimiento pacifista internacional, resalta la conexión de la crisis ecológica con la opresión de las mujeres. Y, al igual que Kelly hará más tarde, recoge en su libro una serie de propuestas de cambio en cuanto a nutrición, salud medioambiental, producción, consumo, condiciones laborales, igualdad entre hombres y mujeres, etc.

3 El ecofeminismo apareció en los años setenta del siglo XX, en las sociedades hiperdesarrolladas, donde grupos de mujeres preocupadas por su salud, por los riesgos que los pesticidas y fertilizantes suponían para la alimentación, y por las consecuencias secundarias de la ginecología ortodoxa, invasiva y demasiado medicalizadora para el cuerpo femenino, comenzaron a dudar de los expertos y a buscar tratamientos alternativos (Puleo, 2011). Así, podemos establecer que los temas fundamentales que favorecieron la aparición del ecofeminismo fueron la preocupación por la salud, el miedo a un holocausto nuclear, el pacifismo y la aparición del movimiento de liberación animal. 
Estado y posibilita el cumplimiento de las leyes, el mantenimiento de la paz y la defensa de la libertad. Y, aunque la guerra sea siempre inhumana y cruel, es imprescindible llevarla a cabo -aunque siempre como último recurso (Maquiavelo, 1992)- cuando no se puede mantener la libertad. Kelly, por el contrario, se refiere a la espiral armamentista como una de las mayores amenazas para la vida y como un peligro que hay que atajar, pues no podrá asegurarse la subsistencia de la vida en la Tierra si no se consigue la desmilitarización de la sociedad. No obstante, ésta no es una tarea fácil, ya que, como señala, se fomenta en la sociedad el miedo al Otro y se potencia la desconfianza con el fin de generar una inseguridad que justifique la posesión de armas de todo tipo.

Todo el complejo tecnológico-científico, industrial y militar está degradando el medio ambiente de forma alarmante, convirtiéndolo en tóxico y cancerígeno ${ }^{4}$ (Kelly, 1984a). Han aumentado el número de enfermedades cardiorrespiratorias, y el cáncer se muestra ya como la enfermedad de la civilización de esta época. Nuestra ecofeminista (Kelly, 1991) mantiene que es imprescindible prohibir la fabricación de sustancias nocivas para la salud y que los datos relativos al medio ambiente tienen que ser de libre acceso para todos los ciudadanos.

Como señala María Xosé Agra (Agra, 1997), existe, en el debate ecofeminista, una tensión entre el activismo y la necesidad de repensar. Es imprescindible incluir la reconceptualización teórica, que abarca la desconstrucción y la reconstrucción, sin separarla de la práctica política activa y transformadora. Creo que Kelly compagina de forma eficiente el análisis teórico con el activismo político. Así, exige un cambio radical en la política, de forma que se logre que las opiniones de la sociedad, especialmente las de los grupos más desfavorecidos, se tengan en cuenta a la hora de legislar y desarrollar planes políticos. Es preciso trabajar para invertir la orientación estatal de la política ${ }^{5}$. Esto sólo puede hacerse mediante las organizaciones populares y la educación ${ }^{6}$, a través de las cuales debe abrirse un espacio civil en el que podamos ser sujetos activos y no objetos a las órdenes de quienes detentan el poder.

Para lograr que la política se enfrente a los problemas de forma satisfactoria, resulta imprescindible, a su entender, incluir la ternura como elemento constitutivo del quehacer político ${ }^{7}$. Explica que con el concepto de «ternura» se refiere a «una relación tierna con

4 Ya en 1962, Rachel Carson, en su Primavera Silenciosa, había relacionado la guerra de la humanidad contra la naturaleza con las investigaciones alemanas sobre los gases nerviosos y se había referido al incremento de la leucemia debido a la utilización de la bomba atómica en Hiroshima. Defendió la necesidad de llevar a cabo una revolución moral para lograr un cambio civilizatorio imprescindible para frenar el complejo militar-industrial y su afán destructivo. En palabras de María José Guerra (Guerra, 2004, 126), el eco-bio-centrismo de Carson es «un humanismo y sobre todo una llamada a una ética de la responsabilidad frente a la dañada y maltratada biosfera».

5 La política verde que defiende esta autora, tal y como señala Octavi Piulats (Piulats, 1993), implica una ruptura radical tanto con la tradición de derechas liberal como con la tradición de las izquierdas clásicas, y también con la variante del socialismo real de su época.

6 Dado que los jóvenes son el futuro, afirma que es imprescindible educarles para la paz, para conseguir, así, que desarrollen un futuro no violento. La educación para la paz estudia las causas de la violencia, la opresión y la guerra, y busca nuevos métodos para que los conflictos puedan solucionarse logrando el máximo de justicia y empleando el mínimo de violencia (Kelly, 1997). Si se educa a los jóvenes en la educación para la paz, aprenderán alternativas a la guerra, al militarismo y a la disuasión.

7 Jorge Martín Neira ha resaltado lo subversivo de incluir la ternura en la política. De hecho, este autor considera la concepción que Kelly tiene de la ternura en el plano político como algo «sencillamente revolucionario» (Martín Neira, 1993). 
los animales y las plantas, con la naturaleza, con la ideas, con el arte, con la lengua, con la Tierra, un planeta sin salida de emergencia. Y, por supuesto, la relación con los humanos» (Kelly, 1984b, 27). En esta nueva forma de hacer política, deben convertirse en medios y fines $^{8}$ determinados valores que han sido despreciados: solidaridad, paciencia, cooperación, ternura, tolerancia, afecto y amor. Dada su creencia cristiana $^{9}$, insiste en el principio de amar al prójimo ${ }^{10}$ pero trasladándolo al terreno de la política. Del mismo modo, propone que se establezca el principio del respeto a la vida y la preocupación por todo lo vivo como la piedra angular de la acción política (Kelly, 1988c), entendiendo que el medio ambiente y la sociedad están interconectados de tal forma que la protección de la naturaleza no puede separarse de la conservación de la humanidad.

Para Kelly, la ética y la política tienen que estar unidas indisolublemente, de forma que el trabajo político siempre tiene que atenerse a escalas morales. Como señala Antonio P. Durán (Durán, 1993), esta forma de entender la política nos retrotrae a la época de Aristóteles, en la que la política se entendía como continuación de la ética. También se asemeja a las posiciones mantenidas por Herbert Marcuse en su debate con el movimiento estudiantil alemán en la década de los sesenta, donde defendió la importancia crucial de los argumentos humanitarios y morales, los cuales deben convertirse en fuerzas sociales centrales (Habermas, 1984, citado en Durán, 1993).

Kelly apuesta por volver a incluir la ética en la política, prestando especial atención a los valores del cuidado, que considera principios feministas positivos. Su énfasis en las virtudes relacionadas con las tareas esenciales de apoyo, el trabajo en el hogar y el cuidado de los niños coincide con algunos aspectos de la ética del cuidado como teoría crítica que apuesta por incluir «otra voz» para analizar los problemas éticos y morales desde una perspectiva especial, que prioriza las relaciones interpersonales y la responsabilidad para con los otros (Gilligan, 1985). La ética del cuidado amplía el campo de la filosofía moral, incluyendo en los debates éticos las experiencias reales, y tratando de complementar los principios de justicia y cuidado, para atender correctamente a las situaciones particulares (López de la Vieja, 2004). Los agentes morales, de este modo, dejan de concebirse como individuos exclusivamente autónomos para concebirse como individuos interconectados, con responsabilidades recíprocas.

\section{Acciones no violentas para una sociedad justa}

Hemos visto ya que Kelly defiende la necesidad de transformar la política radicalmente. Con este fin, apuesta por constituir un partido que represente a los más débiles de la socie-

8 El pacifismo de Kelly está claramente influenciado por el pensamiento de Gandhi, en el que el concepto de Ahimsa (no-violencia) se convierte en el eje central (Díaz del Corral, 1987). La no-violencia de Gandhi es un método activo para la liberación individual y social y para la reforma pacífica del hombre y de las estructuras sociales. Gandhi, como Kelly posteriormente, defiende una postura radicalmente antimaquiavélica pues, para él, el fin jamás justifica los medios. De hecho, no encuentra diferenciación entre medios y fines pues, en su opinión, los medios lo son todo.

9 Conviene resaltar que aunque Kelly tuvo una educación católica estricta, abrazó finalmente una mezcla de teología feminista y de la liberación junto con la doctrina budista (Hertsgaard, 1993).

10 Kelly reconoce la influencia que el principio del amor al prójimo y el Sermón de la Montaña tiene en su pensamiento, y considera que este último no es sólo un documento espiritual, sino también un documento político radical (Kelly, 1986b). 
dad. La no violencia, la solidaridad, la preocupación social, la ecología, el feminismo y la democracia de base deberían ser los pilares básicos de este nuevo partido ${ }^{11}$, para tratar de conseguir un cambio estructural. Sin embargo, no basta con fundar un partido con estas características, sino que hay que reforzar sus actuaciones mediante acciones no violentas y desobediencia civil ${ }^{12}$.

La forma de actuar que defiende esta autora se enmarca dentro de la acción social no violenta. Rechaza tajantemente resolver los conflictos de tal forma que siempre haya alguien que pierda. Mediante el uso de la violencia no se pretende alcanzar la reconciliación. Sólo se consigue someter al adversario (Kelly, 1987a). La violencia, pues, nunca es emancipatoria sino que, por el contrario, es autoritaria. Por este motivo, defiende el desarme, el abandono de las posturas hostiles y un cambio en el terreno de la política medioambiental, así como el establecimiento de medidas de anticipación para favorecer la confianza. Del mismo modo, propone transformar la industria militar, convirtiéndola en una industria que produzca manufacturas de uso civil, ecológicamente tolerables y socialmente útiles. Para lograr esto, habría que potenciar la demanda de estos productos e imponer una política de impuestos adecuada.

Para nuestra autora, la paz mundial, estrechamente ligada a la protección del medio ambiente y de los derechos humanos, debe fundarse en la paz interior (Kelly, 1987b) y depende, por tanto, de nuestra propia voluntad (Kelly, 1988b). Charlene Spretnak ha afirmado que Kelly «mantenía un sentido espiritual de bondad y agradecimiento hacia la vida y [que] nunca aceptó una visión derrotista de la condición humana» (Spretnak, 1993, 174). La concepción de la naturaleza humana que defiende Kelly se diferencia, por ejemplo, de antropologías filosóficas más pesimistas, como la de Hobbes, en la que encontramos una noción del hombre como un «lobo» para el hombre. En efecto, Hobbes, en el capítulo XIII de su Leviatán, afirma que los hombres son iguales por naturaleza y que, de esa igualdad de capacidades, surge la igualdad en la esperanza de alcanzar los propios fines. De este modo, si dos individuos desean una misma cosa que no pueden disfrutar ambos, se convierten en enemigos que tratarán de destruirse o someterse para lograr su fin. Por ello, la forma más

11 Kelly participó en 1979 en la fundación de Los Verdes alemanes, partido que en 1983 obtuvo representación parlamentaria en la República Federal Alemana (véase Parkin, 1994). Acuñó el término «partido anti-partido», tomándolo prestado de los disidentes de la Europa oriental (Hertsgaard, 1993). Con este término quería expresar que Los Verdes no aceptaban los compromisos a los que accedían los partidos tradicionales para lograr hacerse con el poder. Los Verdes aparecen como una alternativa de sistema. Se trata de un partido que introduce la conciencia planetaria. Como afirma Martín Neira: «Los Verdes representan la radical novedad con respecto a las anteriores ideologías o partidos de que no pretenden defender a una clase social sino al conjunto de la sociedad planetaria y más allá, al conjunto del planeta considerado el todo como un conjunto ecológico interrelacionado e interdependiente» (Martín Neira, 1993, 9). Leo Cox sostiene que, bajo la autoridad moral de Kelly, al menos hasta mediados de los años ochenta, Los Verdes aparecía más como un movimiento que como un partido. De hecho, todos los movimientos sociales estaban representados o influenciados directamente por las decisiones tomadas por Los Verdes. Es más, la forma de hacer política de este «partido anti-partido» fue adoptada por otros partidos verdes de Europa (Cox, 1993).

12 La desobediencia civil y la acción social no violenta por la que apuesta Kelly se entiende, tal y como mantiene Durán, como una protesta moralmente fundamentada, si tenemos en cuenta, como ha señalado Habermas, que los ciudadanos de cualquier Estado de Derecho tienen que aceptar el ordenamiento jurídico por libre voluntad y no por temor al castigo. La desobediencia civil se entiende, en palabras de Habermas, «como un elemento de una cultura política madura. Todo Estado democrático de Derecho que está seguro de sí mismo, considera que la desobediencia civil es una parte componente normal de su cultura política, precisamente porque es necesaria» (Habermas, 1988, 54, citado en Durán, 1993, 32). 
razonable que tiene el hombre de evitar la inseguridad en la que se encuentra en el estado de naturaleza es dominar e imponer su poder sobre los otros. Si no existe un poder superior que imponga respeto entre los hombres, la dominación y el ejercicio del poder sobre el resto es necesario para la propia conservación, ya que permanece un estado de guerra de todos contra todos (Hobbes, 1983). Nuestra autora, por el contrario, sostiene que las ansias de poder y las actitudes de dominación se deben a la estructura patriarcal que subyace en todos los ámbitos de la sociedad. Los valores patriarcales, pues, son los causantes de las injusticias del mundo. Desde el feminismo ${ }^{13}$ se pretende redefinir nuestros modos de existencia y transformar de forma no violenta las estructuras de la dominación masculina, ya que el sistema patriarcal es opresor para las mujeres y restrictivo para los hombres (Kelly, 1997). El poder que demanda el feminismo no es un poder de dominación, sino un poder que refleje los valores y la experiencia de las mujeres. Es preciso, pues, trabajar para transformar las estructuras patriarcales que conducen a la opresión. Kelly considera que es posible conseguir cambios sociales e individuales que nos lleven a alcanzar una sociedad justa. Por ello, propone cambiar los valores establecidos por otros valores no violentos, como el amor, la compasión y la simpatía, e incluir en la política el coraje, la fantasía y la decisión, para lograr transformar la política establecida que, al igual que la economía, la Iglesia, las escuelas, el ejército y la gran mayoría de las estructuras del Estado, ha sido creada por y para los varones (Kelly, 1984b).

No debemos aceptar, insiste, que se infunda en la población el miedo y la desconfianza, pues esto conduce a la justificación del rearme y de la posesión de armas de destrucción masiva. El adversario no debe convertirse en enemigo al que hay que atacar mediante la fuerza. Kant, en La paz perpetua, había defendido la necesidad de mantener, incluso en estado de guerra, «cierta confianza en la conciencia del enemigo» para que sea posible el restablecimiento de la paz (Kant, 2013). Kelly va un paso más allá y apuesta por partir de la confianza incluso en los considerados enemigos. De lo que se trata es de acercarse al resto de las personas desde el amor y la comprensión, tratando de conseguir un cambio que beneficie a todos, sin imposiciones de ningún tipo.

Lo que debe quedar claro, a su entender, es que la violencia nunca podrá eliminarse mediante la violencia. Por ello, el único camino para alcanzar la justicia es la no violencia, que se fundamenta sobre el principio de la inviolabilidad de la vida humana, extendiendo la preocupación a la protección del medio ambiente, como condición necesaria para la supervivencia de la humanidad ${ }^{14}$. Optar por la resistencia no violenta significa fortalecer y estabilizar de forma dinámica la democracia parlamentaria. La resistencia no violenta no es pasividad ni padecimiento de la violencia y las injusticias, sino que es la manifestación de una energía espiritual, psíquica y moral, que consiste en no hacer nada que implique participar de la injusticia. El respeto a la vida y el deseo de liberación son pilares básicos

13 Los primeros referentes intelectuales de Kelly en lo que respecta al feminismo los encontramos en Rosa Luxemburg, Alexandra Kollontai, George Sand, Emma Goldman o Helen Keller.

14 Como señalan Jesús González Bravo y Luis Hidalgo, «el ideario de Petra Kelly ha sido capaz de demostrarnos que es posible la integración entre dos líneas de pensamiento falsamente incompatibles: por un lado, la necesaria preservación del medio ambiente y los recursos no renovables, y por otro, la que ha situado el bienestar y las necesidades del hombre por encima de cualquier planteamiento conservacionista» (González Bravo, Hidalgo, $1993,33)$. 
de la no violencia. La no violencia es una forma de vida que termina cuando las acciones se convierten en una amenaza para las personas y cuando vulneran la dignidad humana (Kelly, 1985a). Lo que se pretende a través de las acciones no violentas es tratar a los demás como personas, como a nosotros mismos. Se puede decir, pues, que en el pensamiento de Kelly subyace el imperativo de Kant «obra de modo tal que tomes a la humanidad, tanto en tu persona como en la de cualquier otro, siempre al mismo tiempo como un fin y nunca meramente como un medio». De hecho, suenan ecos de la idea kantiana de que en la guerra, la utilización de la gente para que mate o muera convierte al hombre en una mera máquina al servicio de otro, lo cual está en contradicción con los derechos de la Humanidad ${ }^{15}$. En los conflictos, los adversarios también deben considerarse seres humanos, con lo que habrá que liberarlos de la violencia que los esclaviza (Kelly, 1984a). Mediante las acciones no violentas, no se ataca al adversario como persona, sino únicamente a su rol violento. Se trata de transformar su mentalidad y conseguir que cambie su conducta violenta mediante el diálogo.

A través de la resistencia no violenta el hombre se reconcilia consigo mismo, con su especie y con la naturaleza. Mediante el desarme, las personas se vuelven vulnerables. Y aunque esta característica pueda parecer algo negativo, para Kelly es algo indispensable. En este sentido, sostiene que es imprescindible asumir que somos seres vulnerables y potenciar la ternura, la unión, la no violencia, la participación, la solidaridad y la lucha contra la injusticia.

\section{La importancia de la visión ecológica}

Potenciar la política ecológica supone favorecer la paz. Como afirma Kelly, «necesitamos justicia ecológica: un equilibrio ecológico en el contexto de la justicia económica y una justicia económica en el contexto del respeto a la ecología» (Kelly, 1990, 142). Y, para lograr todo esto, es preciso llevar a cabo una transformación radical en el modelo de producción y consumo, implantando una economía sostenible, libre de sustancias tóxicas y en igualdad de condiciones.

$\mathrm{Al}$ estar enfocado únicamente hacia el crecimiento industrial, el sistema capitalista destruye sus propias bases (Kelly, 1988c), así como el medio ambiente y la estabilidad social. Como se expone en el Manifiesto de los Verdes por la paz:

«Un modo de vida y de producción que se basa en la inacabable afluencia de materias primas, y que las maneja con despilfarro, suministra también el motivo para una apropiación violenta de materias primas ajenas. Frente a esto, un manejo responsable de las materias primas, en un modo de vida y de economía inspirada en la ecología, reduce el peligro de que se haga política violenta en nuestro nombre. La política ecológica dentro de la sociedad crea las condiciones previas para la disolución de las tensiones y la capacidad para la paz en el mundo» ${ }^{16}$.

15 Bien es cierto que, aunque Kant defienda la supresión de los ejércitos permanentes, pues suponen una amenaza de guerra para el resto de los Estados, y critique la instrumentalización de los hombres utilizados en la guerra, considera que los ciudadanos que forman un ejército voluntariamente para defender su patria no se convertirían en medios para los fines de otros, sino que seguirían siendo fines en sí mismos.

16 Manifiesto de los Verdes por la paz, Offenbach, 1981, citado en (Kelly, 1984a, 49-50); (Kelly, 1988c, 44). 
La crisis ecológica, según Kelly, no es una crisis de escasez de recursos, sino una crisis de consumo. Los problemas económicos están estrechamente vinculados a los problemas medioambientales. Por ello, los países industrializados tienen que cambiar sus economías basadas en el crecimiento y el consumo, por economías sostenibles centradas en la conservación. Por su parte, los países del Sur deben lograr que el desarrollo económico se ajuste al desarrollo ecológico ${ }^{17}$. No obstante, para conseguir esto, es imprescindible que cese la política explotadora del Norte, pues el desarrollo ecológico equilibrado depende de una justa redistribución de la riqueza del Norte hacia el Sur (Kelly, 1997).

Kelly analiza el sistema agroalimentario basado en la utilización de productos químicos y en las explotaciones intensivas, y realiza unas propuestas ${ }^{18}$ que actualmente encontramos en el programa de acción de Vía Campesina ${ }^{19}$. Los cambios que propone no se centran únicamente en reformas en el sistema agrícola, sino que se extienden a todo el modelo de producción y consumo: «Contra el estilo de vida de usar y tirar, se ofrece solidaridad y amistad. En lugar de aumentar los contingentes de mercancías en el marco

17 Las políticas de desarrollo, según señalan María José Guerra y Aránzazu Hernández (Guerra, Hernández, 2005), cuentan con determinados problemas tanto a nivel teórico como práctico, ya que poseen ambigüedades conceptuales en relación a la clase, el género, las relaciones Norte-Sur y la cuestión ecológica. El paradigma del desarrollo humano no ha sabido articular las convergencias entre las perspectivas de género, desarrollo y medio ambiente en un marco teórico integrador. Hay quien considera, por tanto, que es preciso desechar el desarrollo en tanto que mito del patriarcado capitalista occidental, que sólo ha profundizado la desigualdad humana entre el Norte y el Sur y entre hombres y mujeres, potenciando los roles de género.

18 Mantiene que los monopolios de semillas limitan la variedad genética de los alimentos, dando lugar a terribles catástrofes alimenticias y favoreciendo el hambre en el mundo. Por ello, rechaza las técnicas utilizadas por los países desarrollados, como las llevadas a cabo en la Revolución Verde. Y recuerda que los cultivos intensivos tienen efectos perniciosos y que los métodos empleados por las empresas agroquímicas potencian la uniformidad y la dependencia de los productos químicos. Por el contrario, las familias de agricultores mantienen el poder y la creatividad en los cultivos. Nuestra autora no pretende rechazar frontalmente los adelantos de la tecnología, sino que se utilicen de manera responsable y sostenible (Kelly, 1984a). Defiende una transformación en el sistema de producción agrícola, que implica cambios en las políticas agrarias y la implantación de la agricultura ecológica y biológica como una alternativa rentable y realizable, tanto en los países desarrollados como en los países subdesarrollados y en vías de desarrollo. Este tipo de agricultura permite reducir la cantidad de materias primas fósiles utilizadas en la actualidad, eliminando los abonos minerales y los productos químicos para el tratamiento de las plantas. Al centrarse en las empresas familiares independientes, medianas y pequeñas, fomenta la participación y la pervivencia de los agricultores, y no de las grandes corporaciones agrícolas.

Kelly no acepta la división nacional e internacional del trabajo en diversas unidades económicas, pues genera desequilibrios entre regiones, entre las ciudades y el campo y entre los países industrializados y los del Tercer Mundo. Esta división también da lugar a un aumento de los costes de transporte, incrementándose, a su vez, las necesidades de energía y de suelo utilizable (Kelly, 1988c). Si, por el contrario, se potencia que los centros de producción se sitúen en las cercanías de los consumidores locales y regionales, se logrará minimizar los costes de transporte y consumo de energía.

19 Vía Campesina lucha por la implantación del derecho a la Soberanía Alimentaria. Esta organización plantea un cambio en el modelo productivo, caracterizado actualmente por el agronegocio de las megaempresas. En su lugar, defiende la producción agroecológica y sustentable, libre de plaguicidas y transgénicos, y que reconozca los saberes de las familias campesinas e indígenas (Declaración de Maputo: V Conferencia Internacional de la Vía Campesina, 2008). Del mismo modo, grupos de mujeres han encontrado en la agroecología una forma de empoderarse en la familia y en la sociedad, con lo que han unido sus demandas feministas con las reivindicaciones de Vía Campesina, desarrollando una crítica al sistema capitalista patriarcal. Estas mujeres persiguen el derecho a la Soberanía Alimentaria, el cual sólo se podrá alcanzar cuando se construya un nuevo sistema fundado en valores igualitarios, respetuosos con la vida y ecológicamente sostenibles (Declaración de las mujeres por la Soberanía Alimentaria, 2007). 
de la ampliación de la producción del capital, debe producirse el aumento de la calidad de vida, en armonía con la necesidad de la renovación cíclica y la conservación de la Naturaleza» (Kelly, 1984a, 27-28). Sostiene que el estilo de vida consumista y la agricultura industrializada dan como resultado el aumento del hambre en el mundo ${ }^{20}$. Por ello, resulta evidente que el modelo de producción actual, basado en estructuras capitalistas patriarcales, no hace frente de forma satisfactoria a las demandas de la población mundial, pues genera hambre, desigualdades, problemas de salud y trastornos en los ciclos ecológicos. Para evitar estos males, es preciso instaurar una economía que proteja el medio ambiente y que base el bienestar en el tipo de los métodos de producción y no en la abundancia de los bienes producidos. Los métodos de producción adecuados tienen que preservar el medio ambiente, proteger la salud humana y dar lugar a productos de consumo de larga duración (Kelly, 1988c) $)^{21}$.

Con respecto a esto, conviene recordar la crítica que realiza Marcuse ${ }^{22}$ (Marcuse, 2010) a la sociedad capitalista de consumo. Este autor considera que esta sociedad es tan eficaz que consigue neutralizar cualquier forma de oposición al sistema así como la capacidad crítica de los individuos, que adoptan la conducta social establecida, interiorizan las necesidades artificiales que les impone el sistema y se conforman con el bienestar superficial que se ha conseguido gracias a la mejora del nivel de vida. Bajo la apariencia de una conciencia feliz, los individuos reproducen las estructuras de dominación impuestas por la sociedad. A la luz de estas reflexiones, ¿no parece que nuestra autora tiene un excesivo optimismo con respecto a las posibilidades de reacción de los sujetos modelados por el sistema capitalista?23 Para responder a esta pregunta, creo que antes deberíamos recordar que incluso el propio

20 Para un estudio sobre el derecho al alimento véase (Ausín, 2010). Este autor subraya que el hambre no es una fatalidad, sino una injusticia. La falta de alimentos, defiende, no se debe a la escasez de recursos, sino a una redistribución desigual de los mismos. Los alimentos y el agua deben considerarse no bienes comercializables, sino bienes públicos y sociales. Únicamente de esta manera se podrá ampliar la protección sobre ellos y garantizar su acceso universal. Recalca que proteger el derecho al alimento debe ser una prioridad política tanto nacional como internacional y que debería poder exigirse tanto política como jurídicamente, pues no se trata de un «objetivo deseable» sino de una necesidad absoluta y universal. El considerar el acceso al alimento y al agua potable un derecho humano básico y universal implica la necesidad de protegerlo y garantizarlo tomando determinadas medidas políticas, tanto de emergencia como de carácter técnico y estructural en los sistemas de producción, distribución y comercialización de los alimentos y el agua.

21 Cuán lejos de esta aspiración se encuentra la producción actual que se basa en la obsolescencia programada para conseguir aumentar el consumo.

22 Marcuse fue uno de los referentes teóricos de los movimientos revolucionarios de los años sesenta y setenta, que tuvieron lugar cuando Kelly se encontraba en Estados Unidos y que, sin duda, tuvieron repercusión en el pensamiento de esta autora. Aunque Kelly participó en los movimientos en favor de los movimientos civiles y en contra de la guerra, no se implicó, tal y como relata su mentor en la universidad americana, el doctor Abdul Aziz Said (citado en Hertsgaard, 1993), en los movimientos estudiantiles americanos pues, aunque estaba de acuerdo con los objetivos, consideraba que tanto los líderes como los integrantes de movimiento estudiantil no eran verdaderamente revolucionarios, aunque trataban de parecerlo.

23 Kelly no renuncia a la perspectiva utópica. De hecho, considera indispensable el planteamiento de cuestiones utópicas. Utilizando el concepto de utopía de Max Horkheimer, Durán afirma que «el sueño del «verdadero»y «justo orden de vida» de Petra K. Kelly puede decirse que se aleja de las utopías novelescas del Renacimiento y de la Ilustración [...] puesto que en su tarea política no pierde de vista las premisas sociales del proceso vital de las sociedades actuales» (Durán, 1993, 28). La utopía que pretende Kelly no se reduce a la exigencia de una sociedad perfecta atemporal, sino que se asienta en las condiciones materiales resultantes del proceso vital, de forma que aspira a acabar con las injusticias del mundo mediante la transformación de las bases de la sociedad. 
Marcuse, a pesar de que considera que los esfuerzos individuales y colectivos tienen pocas posibilidades de trastocar la estructura de la sociedad, mantiene la esperanza en la posibilidad de transformaciones profundas.

En la sociedad ecológica a la que aspira $\mathrm{Kelly}^{24}$, todos los aspectos de la vida -economía, estilo de vida, deseos de los consumidores, etc.- deben girar en torno a la idea de respeto a la salud humana y al medio ambiente, y de cuidado de la flora y la fauna. Por esto, la buena salud, el aire puro, el agua limpia, los alimentos no envenenados y la existencia de una variedad de animales y plantas compartiendo nuestro entorno deben considerarse los criterios del verdadero bienestar ${ }^{25}$ (Kelly, 1990), por lo que tienen que convertirse en la base de nuestro pensamiento político y económico occidental, para así garantizar la dignidad y la vida en el resto del planeta.

Kelly defiende una postura que sea respetuosa con la vida, y esto en sentido amplio. Los modos de vida y las políticas responsables sólo serán efectivos si fomentan la paz, la libertad, la igualdad y el respeto por la naturaleza. Es preciso, pues, tomar conciencia de los lazos inquebrantables que unen el medio ambiente, la economía, los derechos humanos y la paz, y llevar a cabo, desde una perspectiva ecológica, transformaciones radicales en la sociedad y en la economía. En el sistema que propone (Kelly, 1997), los seres humanos no explotarían la naturaleza como un mero recurso sin límites, sino que establecerían con ella una relación de asociación basada en la interdependencia ${ }^{26}$.

24 Considero que el concepto de ciudadanía ecológica que ha propuesto Andrew Dobson (Dobson, 2005) se ha convertido en un elemento fundamental para lograr alcanzar la sociedad ecológica por la que Kelly trabajó. La ciudadanía ecológica trata de deberes que no tienen carácter contractual y se refiere tanto a la esfera pública como a la privada. Atiende no tanto a la naturaleza del deber cuanto a su origen para poder determinar, así, cuáles son las virtudes necesarias para la ciudadanía. Trabaja con el lenguaje de la virtud y es explícitamente no-territorial. La principal obligación de la ciudadanía ecológica es conseguir que el impacto de las huellas ecológicas sea sostenible, asegurando, de este modo, que el resto de los individuos, del presente y del futuro, puedan desarrollar las acciones importantes para ellos. La ciudadanía ecológica abarca las virtudes de la ciudadanía liberal y de la republicana, pero va más allá de ellas. La primera virtud del ciudadano ecológico es la justicia, ya que lo que hay que hacer es asegurar una distribución justa del espacio ecológico. Para que la justicia se ejerza de forma efectiva, deben incluirse determinadas virtudes secundarias, como la simpatía, el cuidado y la compasión.

25 Carmen Velayos (Velayos, 2005) ha llamado la atención sobre el hecho de que el recurso al temor ha predominado en la ecoética como motor de la acción, por encima de la apelación a la felicidad. Estudios psicológicos demuestran que el recurso al temor no es muy eficaz a la hora de transformar las actitudes y los comportamientos, y que los refuerzos positivos contribuyen a forjar comportamientos pro-ambientales duraderos. Así, aunque Velayos considera necesario el recurso al temor a un mundo insostenible, pues facilita que nos hagamos responsables de nuestros actos, apuesta también por incluir el recurso a la felicidad. Afirma que podemos actuar de forma correcta desde el punto de vista ecológico porque consideramos que es nuestro deber y porque constatamos al mismo tiempo que esto nos hace felices. Esta autora aspira a lograr una educación ambiental emocional que permita la formación de ciudadanos que obtengan placer cuando se comporten de forma justa y correcta. Así, junto a la reflexión sobre lo que perdemos si no nos comportamos de manera sostenible, aparece la reflexión sobre lo que ganamos si lo hacemos.

26 Puilats diferencia tres etapas en el pensamiento de Kelly: una primera etapa correspondiente a los años en los que vivió en Estados Unidos; una segunda etapa que coincide con su vuelta a Europa; y una tercera etapa en la que recupera la espiritualidad de sus orígenes. En esta última fase, realiza un giro intelectual dentro de la política verde, advirtiendo - probablemente influenciada por la cultura Tibetana, tal y como mantiene el autor (Piulats, 1993)- que el movimiento verde tiene que enfrentarse al peligro del ambientalismo, es decir, que esta política tiene que ir más allá de la colocación de algunos filtros y la promoción de algunos programas de educación ambiental que la sociedad de consumo debe seguir. Por ello, Kelly apuesta por que el movimiento verde se dirija hacia la ecología profunda y se libere de los valores industriales que impiden que nuestra actitud hacia la naturaleza se transforme de manera significativa. 


\section{La visión de género en el pacifismo y el ecologismo: buscando la igualdad en todos los ámbitos}

Conviene recordar que, básicamente, en todos los sistemas socioculturales, a los hombres se les concede más valor que a las mujeres. Poseen, también, más poder social y económico. Y aunque existan otras estructuras de dominio, el dominio de los hombres sobre las mujeres es una característica constante, que pervive en todos los demás sistemas de opresión (Kelly, 1985b). Como afirma Kelly, «el sistema patriarcal ha expoliado hasta hoy la naturaleza y la humanidad, enviando después a las personas a recobrar fuerzas al «mundo femenino»» (Kelly, 1984b, 30). La mayoría de los hombres y numerosas mujeres consideran la desigualdad y la dominación como algo natural, por lo que dan por hecho que es imposible cambiarlo. Sin embargo, para Kelly (Kelly, 1986a) es evidente que ninguna forma de dominación pertenece a la naturaleza humana, y que las normas de comportamiento de las personas pueden modificarse, por lo que es necesario transformar la situación de discriminación de las mujeres. Kelly es consciente de que prevalece un pensamiento fuertemente patriarcal, que incluso llega a convertirse en misógino y glorificador de la violencia. Y, sin embargo, la sociedad no se toma muy en serio las humillaciones y vejaciones que sufren las mujeres (Kelly, 1988a). Por ello, apuesta por reconocer la protección contra el sexismo como un derecho humano.

Afirma que todas las dominaciones e injusticias están conectadas, pues se deben a una estructura patriarcal, racista y sexista, que promueve una mentalidad militarista, por lo que sólo se alcanzará la justicia social si, mediante acciones no violentas, se consigue acabar con todos los sistemas de dominación masculina. Por ello, las preocupaciones del movimiento ecologista, de los grupos por la paz y por la justicia social, contra la pobreza mundial y por las cuestiones laborales están relacionadas (Kelly, 1997). Los movimientos ecologistas deberían aprender a interconectarse con otros movimientos reivindicativos como son el movimiento pacifista, el feminista o el movimiento en defensa de los derechos humanos (Kelly, 1988c), tratando de alcanzar la justicia social, eliminando el dominio y la opresión, incluida la opresión -tanto estructural como individual- de las mujeres ${ }^{27}$.

El poder patriarcal conduce a la catástrofe ecológica, al militarismo y al sufrimiento personal y, ya que todos los sistemas de opresión comparten la dominación de las mujeres, es necesario cambiar la definición de «poder» de forma que sea un poder feminista, es decir, un poder basado en la experiencia de las mujeres ${ }^{28}$, que es un poder con los otros y no sobre los otros (Kelly, 1997). Como ya he apuntado en el apartado 3, Kelly considera que las injusticias del mundo se deben a las estructuras de dominación masculina y al tipo de poder propio del patriarcado. Por ello, afirma que es preciso abolir el poder tal y como lo conocemos mediante actos no violentos. Se trata de redefinir el poder y concebirlo como un poder compartido, es decir, como un poder que pueda ser usado por todas las personas para el beneficio común (Kelly, 1985b). Sin duda, no se trata de reemplazar el dominio

27 Kelly (Kelly, 1997) señala que muchos movimientos de liberación no se cuestionan el dominio masculino, sino que lo dan por hecho, por lo que no se toman realmente en serio la opresión de las mujeres.

28 Con respecto a esto, hace referencia a las ideas que Jean Baker Miller sostiene en su libro Toward a New Psychology of Women. Esta autora señala que, como mujeres, aunque excluidas del dominio masculino del poder, tenemos la experiencia de un gran poder en la tarea cotidiana de alimentar y criar a otros seres. 
de los varones por el dominio de las mujeres, pues eso perpetuaría el modelo patriarcal de domino. De lo que se trata, por el contrario, es de transformar el modelo radicalmente.

Sostiene que «hay una relación clara y profunda entre militarismo, degradación ambiental y sexismo» (Kelly, 1997, 29). Por ello, es necesario alcanzar una perspectiva que considere todos los problemas de una manera holística. La ecología, el feminismo y la paz deberán tratarse en bloque, pues son paralelos y comparten objetivos. En este sentido, no acepta la inclusión de las mujeres en el aparato militar, ya que la emancipación no es sólo la autodeterminación, sino que es también el cuestionamiento del dominio de los hombres y sus conquistas.

Una sociedad pacífica, justa y ecológica sólo puede fundarse en la igualdad de los sexos, y esta igualdad no puede conseguirse mediante la incorporación de las mujeres en actividades bélicas. Según nuestra autora, no debe considerarse un comportamiento feminista el pretender acceder a todos los terrenos laborales, sin tener en cuenta lo inhumanos que puedan llegar a ser. La igualdad de derechos no se conseguirá asumiendo los valores patriarcales ni incorporándose a las estructuras que dan lugar a la explotación, la violencia y la guerra, sino realizando tareas respetuosas con las personas y el medio ambiente (Kelly, 1986a). Por ello, es necesario eliminar los ejércitos y el resto de trabajos basados en la dominación. Como vemos, en Kelly, junto a la crítica al sexismo, aparece la crítica y el rechazo al androcentrismo. Será imprescindible analizar los diferentes ámbitos de la sociedad para descubrir los discursos y los componentes de género que subyacen de forma más o menos encubierta, pues no basta con que exista representación femenina en las diferentes esferas socioculturales, sino que la presencia de las mujeres tiene que acompañarse de la defensa de los valores feministas.

A lo largo de los siglos, los ejércitos han servido para afianzar las estructuras patriarcales. Por ello, Kelly no acepta que se considere que la incorporación a los ejércitos por parte de las mujeres sea una conquista de derechos y de igualdad. Del mismo modo, critica que se promueva el acceso de las mujeres al ejército bajo la justificación de que la adquisición de los mismos derechos por parte de las mujeres tiene que ir acompañada también de la adquisición de las mismas obligaciones. La autora recuerda la sobrecarga de obligaciones sociales que arrastran las mujeres y que rara vez comparten con los varones (Kelly, 1984a). Por ello, considera injusto que los políticos y los Estados no obliguen a los hombres a participar de las mismas obligaciones que las mujeres en cuanto al trabajo doméstico y la crianza de los hijos, y no ofrezcan alternativas para que pueda ser un trabajo compartido, mientras que sí que facilitan que las mujeres pasen a formar parte de las estructuras y trabajos patriarcales.

Según Kelly, el pacifismo y la no violencia no pueden ser exitosos si se separan de las reivindicaciones feministas. Sin embargo, hay que resaltar que no acepta la teoría de que las mujeres estén naturalmente dispuestas para la paz y que ellas sean las guardianas de la vida en la Tierra. Hay que rechazar y combatir la identidad natural entre pacifismo y naturaleza femenina. Recuerda que las mujeres no son totalmente ajenas a los productos del patriarcado como, por ejemplo, las guerras. De hecho, muchas mujeres creen en las guerras justas y las apoyan con entusiasmo. Igualmente, observa que las mujeres han desempeñado papeles activos en las guerras, como sostén y auxiliar de los hombres que hacían la guerra (Kelly, 1986a). Por ello, es imprescindible transformar el pensamiento de aquellas mujeres que han aceptado los valores y las normas del mundo masculino, amoldándose al poder de los hombres, y asumiendo sus imperativos y su modo de pensar. Como vemos, la crítica al androcentrismo es constante en esta autora. 
El pacifismo y el feminismo se complementan necesariamente, en una crítica y un rechazo a la sociedad militarista y patriarcal, y tratan de mostrar que la única alternativa posible para la supervivencia del planeta es un cambio estructural que transforme las bases de un sistema injusto basado en la dominación (Kelly, 1984a). Es preciso fomentar la hermandad de las mujeres, pues el sistema patriarcal trata de mantenerlas divididas (Kelly, 1997). La sororidad aparece como una de las reivindicaciones fundamentales de la agenda feminista actual. Kelly supo ver la necesidad de tejer redes de apoyo entre mujeres y de potenciar los valores feministas.

Pretende lograr «una cultura suave y alternativa, donde lo personal sea político y lo político personal» (Kelly, 1984b, 30). En el cambio del sistema capitalista patriarcal no debe contar únicamente la lucha de las mujeres. También los hombres tienen que ser conscientes de los peligros de este sistema, trabajando junto con las mujeres para conseguir una transformación radical. Para este fin, es necesario que los varones tomen conciencia de su responsabilidad de transformarse a sí mismos desarrollando las cualidades humanas relacionadas con el afecto y participando en el cuidado de los niños, en el trabajo del hogar y en todas las demás tareas esenciales de apoyo.

\section{Resumen y conclusiones}

Como hemos podido ver a lo largo de estas páginas, todas las problemáticas a que hace frente la humanidad y el planeta están interconectadas y deben abordarse de manera conjunta, si de lo que se trata es de resolver la situación de crisis a que nos enfrentamos en la actualidad. Petra Kelly analiza esta interconexión, tratando de buscar sus causas y así lograr una comprensión adecuada de la situación, que nos permita realizar transformaciones profundas en la sociedad. Su propuesta en este sentido parte de la necesidad de incluir, tanto en el ámbito político como en el activismo individual, las cualidades humanas relacionadas con el afecto, el amor y la amistad. Según esta autora, únicamente si se presta atención a determinados valores que tradicionalmente han sido menospreciados, se conseguirán los resultados que se esperan.

Como argumenta Kelly, resulta evidente que la militarización de la sociedad, la utilización de la energía nuclear y el uso de la violencia como método para la resolución de conflictos constituyen una amenaza para la vida, por lo que es imprescindible realizar transformaciones radicales en las políticas de seguridad, favoreciendo la confianza y la tolerancia. La defensa basada en la violencia y las armas debe sustituirse por la acción social no violenta, pues sólo así podrá conseguirse la reconciliación con el adversario. Y como la paz se encuentra en concordancia con la protección del medio ambiente y de los derechos humanos, podemos afirmar que, únicamente si se trabaja por eliminar la violencia, se podrán conseguir unas condiciones socialmente justas, que incluyan un medio ambiente ecológicamente sano. Dado que el medio ambiente y la sociedad están conectados de tal forma que de la preservación de uno depende la conservación del otro, es imprescindible conceder a los temas ambientales la importancia adecuada, pues la justicia ecológica es condición necesaria para la justicia social. De hecho, la degradación medioambiental compromete seriamente el propio cumplimiento de los derechos humanos.

Kelly considera que todas las transformaciones que hay que realizar en el sistema únicamente serán exitosas si se comprende que la causa de las injusticias es la estructura patriarcal 
que subyace en todas las sociedades y si se trabaja por eliminar la desigualdad y el dominio de los hombres sobre las mujeres. Así, comprendemos que, para acabar con la dominación, la opresión y la injusticia, resulta imprescindible transformar la noción actual de poder, de forma que consigamos un poder compartido y no un poder jerárquico y autoritario. Sólo de este modo se producirá el cambio estructural necesario para transformar las bases del actual sistema basado en la dominación.

La evolución de las políticas estatales es imprescindible para lograr la sociedad por la que Kelly trabaja. Será necesaria una forma de hacer política en la que se tome realmente en serio tanto a las personas como a la naturaleza. No obstante, ese cambio es algo necesario pero no suficiente, pues debe ir acompañado de transformaciones radicales en cada uno. Cada persona ha de interiorizar valores como la solidaridad, la cooperación, la tolerancia, la ternura y el amor. Por ello, la educación juega un papel fundamental para formar ciudadanos activos y comprometidos con la justicia, capaces de organizarse pacíficamente para resolver los conflictos de tal forma que todos, personas y naturaleza, salgamos beneficiados.

Hemos podido comprobar que en el pensamiento de Kelly subyace una ética de la virtud. Se enfrenta a las cuestiones relativas a cómo se debe vivir para configurar un carácter digno de admiración. Pasa de la política de la vida cotidiana a la política global, y plantea una política de la vida buena. En algunos momentos, la lectura de sus textos nos deja la impresión de que se reduce a un voluntarismo eticista. Sin embargo, no se queda ahí, pues desemboca en un activismo comprometido y en propuestas ético-políticas concretas y bien fundamentadas.

Kelly apuesta por reemplazar el sistema sexista, injusto y ecológicamente insostenible en el que vivimos, por uno comprometido con la paz, con la protección del medio ambiente y con la defensa de los derechos humanos. Este objetivo sólo podrá alcanzarse mediante la lucha no violenta de mujeres y hombres. Por ello, únicamente cuando entendamos que la estructura patriarcal da como resultado el mantenimiento de la opresión, la dominación y la injusticia, y cuando unamos nuestras fuerzas en contra de todos los sistemas de dominación, tendremos la capacidad de crear una sociedad pacífica, igualitaria y sostenible que garantice una vida mejor tanto para la humanidad como para el resto de las criaturas del planeta.

\section{Bibliografía}

Agra, M. X. (comp.) (1998), «Introducción: Feminismo y ecofeminismo», en: Agra, M. X., (comp.): Ecología y feminismo, Granada, Editoria Comares, pp. 1-21.

Ausín, T. (2010), «El derecho a comer: los alimentos como bien público global», Arbor, revista de Ciencia, Pensamiento y Cultura, volumen 186, $\mathrm{n}^{\circ} 745$, Consejo Superior de Investigaciones Científicas, Madrid, pp. 847-858.

Cockburn, C. (2009), Mujeres ante la guerra. Desde donde estamos, Barcelona, Icaria.

Cox, L. (1993), «Una militante del partido anti-partido», en: Muñoz, Á. (comp.): Homenaje a Petra Kelly. La esperanza es verde, Madrid, Calenda, pp. 42-43.

Díaz del Corral, E. (1987), Historia del pensamiento pacifista y no violento contemporáneo, Barcelona, Hogar del libro.

Dobson, A. (2005), «Ciudadanía ecológica», Isegoría (Madrid), n 32, 2005, pp. 47-62.

Durán, A. P. (1993), «La política como ética», en: Muñoz, Á. (comp.): Homenaje a Petra Kelly. La esperanza es verde, Madrid, Calenda, pp. 27-32. 
Galtung, J. (1985), Sobre la paz, Barcelona, Fontamara.

Gilligan, C. (1985), La moral y la teoría. Psicología del desarrollo femenino, México, Fondo de Cultura Económica.

González Bravo, J., Hidalgo, L. (1993), «Una luchadora por encima de los colores», en: Muñoz, Á. (comp.): Homenaje a Petra Kelly. La esperanza es verde, Madrid, Calenda, pp. 33-35.

Guerra Palmero, M. J. (2004), «¿Un vínculo privilegiado mujer-naturaleza? Rachel Carson y el tránsito de la sensibilidad naturalista a la conciencia ecológica», en: Cavana, M.L., Puleo, A., Segura, C. (coords.): Mujeres y ecología: Historia, pensamiento, sociedad, Madrid, Al-Mudayna, pp. 119-127.

Guerra Palmero, M. J., Hernández Piñero, A. (2005), «Mujeres, desarrollo y medio ambiente: Hacia una teoría ecofeminista de la justicia», Isegoría (Madrid), $\mathrm{n}^{\circ} 32,2005$, pp. 185-200.

Hertsgaard, M. (1997), «El legado de Petra K. Kelly», en: Kelly, P.: Por un futuro alternativo, Barcelona, Paidós, pp. 157-172.

Hobbes, T. (1983), Leviatán, Madrid, Editora Nacional.

Kant, I. (2013), La paz perpetua, Madrid, Tecnos.

Kelly, P. (1984a), Luchar por la esperanza. Sin violencia hacia un futuro verde, Madrid, Ed. Debate.

Kelly, P. (1984b), «Ternura en la política», en: Kelly, P. (1992): Pensar con el corazón. Textos para una política sincera, Barcelona, Círculo de Lectores, pp.27-31.

Kelly, P. (1985a): «La no violencia es más fuerte que la violencia», en: Kelly, P. (1992): Pensar con el corazón. Textos para una política sincera, Barcelona, Círculo de Lectores, pp. 305-309.

Kelly, P. (1985b), «La violencia termina donde empieza el amor», discurso ante la Asamblea General de la Juventud en las Naciones Unidas (1985), en: Kelly, P. (1992): Pensar con el corazón. Textos para una política sincera, Barcelona, Círculo de Lectores, pp. 293-301.

Kelly, P. (1986a), «Ideas para la eliminación del patriarcado internacional», discurso en el congreso «Feminismo y ecología», en: Kelly, P. (1992): Pensar con el corazón. Textos para una política sincera, Barcelona, Círculo de Lectores, pp. 336-352.

Kelly, P. (1986b), «Isabella y la tertulia masculina de Bonn. Un diálogo sobre la moral política», en: Kelly, P. (1992): Pensar con el corazón. Textos para una política sincera, Barcelona, Círculo de Lectores, pp. 329-335.

Kelly, P. (1987a), «Llevar el derecho a las naciones», plegaria política en el Día de la Iglesia Evangélica de 1987, en: Kelly, P. (1992): Pensar con el corazón. Textos para una política sincera, Barcelona, Círculo de Lectores, pp. 263-271.

Kelly, P. (1987b), «Nuestra meta es una Europa neutral y humana», discurso en el Foro por la Paz de Moscú, en: Kelly, P. (1992): Pensar con el corazón. Textos para una política sincera, Barcelona, Círculo de Lectores, pp. 250-253.

Kelly, P. (1988a), «¿Es inviolable la dignidad de la mujer?», en: Kelly, P. (1992): Pensar con el corazón. Textos para una política sincera, Barcelona, Círculo de Lectores, pp. 356-359.

Kelly, P. (1988b), «Menos «hombres de Estado» y más «personas civiles»», discurso ante el congreso federal «Caminos hacia la defensa social», en: Kelly, P. (1992): Pensar con el corazón. Textos para una política sincera, Barcelona, Círculo de Lectores, pp. 189-195. 
Kelly, P. (1988c), «Pensar globalmente, actuar localmente. Necesitamos lazos con las bases», discurso ante la Conservation Foundation australiana, en: Kelly, P. (1992): Pensar con el corazón. Textos para una política sincera, Barcelona, Círculo de Lectores, pp. 39-54.

Kelly, P. (1990), «La necesidad de justicia ecológica», en: Kelly, P. (1992): Pensar con el corazón. Textos para una política sincera, Barcelona, Círculo de Lectores, pp. 142-148.

Kelly, P. (1991), «Los niños y las sustancias tóxicas. ¿Qué pasa con los derechos ecológicos de la infancia?», en: Kelly, P. (1992): Pensar con el corazón. Textos para una política sincera, Barcelona, Círculo de Lectores, pp. 275-280.

Kelly, P. (1997), Por un futuro alternativo, Barcelona, Paidós.

Leppänen, K. (2004), «En paz con la Tierra», en: Cavana, M.L., Puleo, A., Segura, C. (coords.): Mujeres y ecología: Historia, pensamiento, sociedad, Madrid, Al-Mudayna, pp. 109-118.

López de la Vieja, M. T. (2004), La mitad del mundo. Ética y Crítica feminista, Salamanca, Publicaciones de la Universidad de Salamanca.

Maquiavelo, N. (1987), Discursos sobre la primera década de Tito Livio, Madrid, Alianza.

Maquiavelo, N. (1992), El príncipe, Madrid, Espasa-Calpe.

Marcuse, H. (2010), El hombre unidimensional: ensayo sobre la ideología de la sociedad industrial avanzada, Barcelona, Ariel.

Martín Neira, J. (1993), «Quién fue Petra Kelly?», en: Muñoz, Á. (comp.): Homenaje a Petra Kelly. La esperanza es verde, Madrid, Calenda, pp. 8-14.

McMahan, J. (2004), «Guerra y paz», en: Singer, P. (ed.): Compendio de Ética, Madrid, Alianza Editorial, pp. 521-535.

Muguerza, J. (2004), «De Bello Mesopotámico o ¿qué hace una chica como tú en un sitio como éste? (La ética ante la guerra de Irak)», en: Ausín, T., Mate, R., Roldán, C. (coords.): Guerra y paz en nombre de la política, Madrid, Calamar Ediciones, El rapto de Europa, pp. 167-173.

Parkin, S. (1994), The Life and Death of Petra Kelly, Great Britain, Pandora.

Piulats, O. (1993), «El pensamiento de Petra Kelly», en: Muñoz, Á. (comp.): Homenaje a Petra Kelly. La esperanza es verde, Madrid, Calenda, pp. 15-17.

Puleo, A. (2011), Ecofeminismo para otro mundo posible, Madrid, Cátedra.

Ródenas Utray, P. (2014a), «Introducción. Paz y justicia adversus guerra y violencia», en: Quesada, F. (coord.): Paz para la paz. Prolegómenos a una filosofía contemporánea sobre la guerra, Barcelona, Horsori Editorial, pp. 7-20.

Ródenas Utray, P. (2014b), «De las sociedades bélicas a las sociedades justas», en: Quesada, F. (coord.): Paz para la paz. Prolegómenos a una filosofía contemporánea sobre la guerra, Barcelona, Horsori Editorial, pp. 333-366.

Spretnak, C. (1997), «Una conmemoración viva», en: Kelly, P.: Por un futuro alternativo, Barcelona, Paidós, pp. 173-180.

Velayos Castelo, C. (2005), «Deberes y felicidad en la ecoética», Isegoría (Madrid), $\mathrm{n}^{\circ} 32$, 2005, pp. 145-156.

- Declaración de las mujeres por la Soberanía Alimentaria, Nyéléni, 27 de Febrero de 2007, en: http://www.ecoportal.net (Consultado el 10/2/2014).

- Declaración de Maputo: V Conferencia Internacional de la Vía Campesina, 28 de octubre de 2008, en: http://www.mujeresenred net (Consultado el 18/2/2014). 
